\title{
Residual Stress Distribution Analysis in Advanced Materials by Neutron Diffraction: The Case of Spherical Storage Tank Butt Weld
}

\author{
Charles Hervoches ${ }^{1, a}$, Miroslav Vrána ${ }^{1}$, Pavol Mikula ${ }^{1}$, L'uboš Mráz ${ }^{2}$, Peter Baksa $^{2}$ and Milan Baláž ${ }^{2}$ \\ ${ }^{1}$ Nuclear Physics Institute ASCR, v.v.i. 25068 Řež, Czech Rep. \\ ${ }^{2}$ Welding Research Institute - Industrial Inst., Račianska 71, 83259 Bratislava, Slovak Rep.
}

\begin{abstract}
The two-axis diffractometer SPN-100 at the Center of Accelerators and Nuclear Analytical Methods (CANAM) in Řež, is a neutron diffraction instrument dedicated to residual stress analyses in polycrystalline materials, it has recently been equipped with a new twodimensional position sensitive detector (2D-PSD) and a six-axis robotic arm for sample positioning. Recent results of strain/stress distribution measurements with the upgraded tools are presented. The measured materials are made of C-Mn unalloyed steel used for spherical storage tank. Welding-induced residual stresses have direct influence on ductility and toughness of both weld metal and heat affected zone of the weld area, which affect the service life time of structures. Normal, transversal and longitudinal components of the stresses obtained in the vicinity of the butt weld from a spherical storage tank were measured by neutron diffraction at CANAM.
\end{abstract}

\section{Introduction}

Residual stresses are phenomena that develop in all welded structures due to local heating. Stresses have direct influence on ductility and toughness of both weld metal and heat affected zone of the weld area and also on service life time of the steel structures. The identification of the residual stress distribution is one of the important parts of the analysis for the evaluation of residual life time of steel structures and estimation of critical defect size of the structure. Stresses are responsible for local deformation of weld area and influence properties and behaviour of these structures during service. The initiation of reheat and stress corrosion cracking limit the life time of steel structures. Combined effect of material quality, environment and level of stresses, residual and/or external, play an important role. Cracks/defects that are larger than the tolerated limit have to be either removed or repaired. This approach is used for storage tanks used for holding of anhydrous ammonia, LPG, NGL, gasoline, naphtha, butadiene, ethylene, hydrogen, oxygen, nitrogen, argon, LNG (liquefied natural gas), biogas, sewage gas and waste water.

Previous neutron diffraction measurement of stress distribution in spherical storage tank butt weld made of C-Mn unalloyed steel, measured at three different distances $(3.5 \mathrm{~mm}, 7.5 \mathrm{~mm}$ and $11.5 \mathrm{~mm})$ below the specimen's surface, demonstrated that the highest tensile stresses are located close to the weld root surface in the weld metal [1]. This contribution presents the results of strain/stress

\footnotetext{
${ }^{\text {a }}$ Corresponding author : hervoches@ujf.cas.cz
} 
distribution measurements, obtained by the neutron diffraction method, in the close vicinity of the butt weld from the spherical storage tank.

\section{Experimental}

The investigated storage tank material has is made of C-Mn unalloyed steel, strength of approx. 430 $\mathrm{MPa}$ and thickness of $30 \mathrm{~mm}$. A specimen of dimensions of $150 \times 200 \times 15 \mathrm{~mm}$ was prepared for the measurements. Normal, transverse and longitudinal components have been measured for the through thickness positions $2 \mathrm{~mm}$ below the surface, on the neutron diffraction strain/stress scanner SPN-100 $[2,3]$ installed at the research reactor LVR-15 in Řež [4]. The instrument is equipped with a focusing $\mathrm{Si}(111)$ monochromator and a 2D position sensitive detector (Figure 1). The specimen was attached to a six-axis robotic arm for positioning in the appropriate orientations for measurement of the normal, transverse and longitudinal strain components measurements (Figure 2).

The measurements were done at a fixed position of the 2D detector with the centre of the detector positioned at an angle of $2 \theta=65^{\circ}$ and an angular range of 12 degrees, allowing the observation of the (110) crystallographic plane of the ferrite, a $-\mathrm{Fe}(110)$. The constant neutron wavelength was 0.213 $\mathrm{nm}$. A sample gauge volume of $3 \mathrm{~mm} \times 3 \mathrm{~mm} \times 3 \mathrm{~mm}$ was defined using fixed cadmium slits in the incident and diffracted neutron beam.

The strain determination is based on measurements of angular deviation $\Delta \theta$ hkl of the diffraction profile position from the value related to the stress-free state. The differentiated Bragg's equation gives a relative lattice strain $\varepsilon_{\mathrm{hkl}}$ according to the formula:

$$
\varepsilon=\frac{\Delta d}{d_{0}}=\frac{\sin \theta_{0}}{\sin \theta}-1
$$

Where $\mathrm{d}_{0}$ is the stress-free interplanar spacing.

The stress components $\sigma \mathrm{x}, \sigma \mathrm{y}$, and $\sigma \mathrm{z}$ are consequently obtained using Hooke's law:

$$
\sigma_{x}=\frac{\mathrm{E}}{(1-2 v)(1+v)}\left[(1-v) \varepsilon_{x}+v\left(\varepsilon_{y}+\varepsilon_{z}\right)\right]
$$

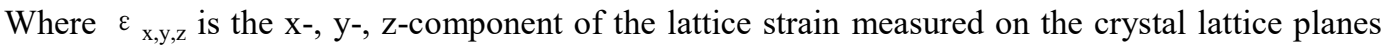
(hkl), E the diffraction elastic Young's modulus, and $\mathrm{v}$ the diffraction Poisson's ratio of the considered material.

For a $-\mathrm{Fe}(110)$, Young's modulus $\mathrm{E}=225.5 \mathrm{GPa}$, and Poisson's ratio $\mathrm{v}=0.28$ values were used. The SteCa software [5] was used to extract $2 \theta$ scattering angle and FWHM of the diffraction peaks from the recorded 2D diffraction images. 

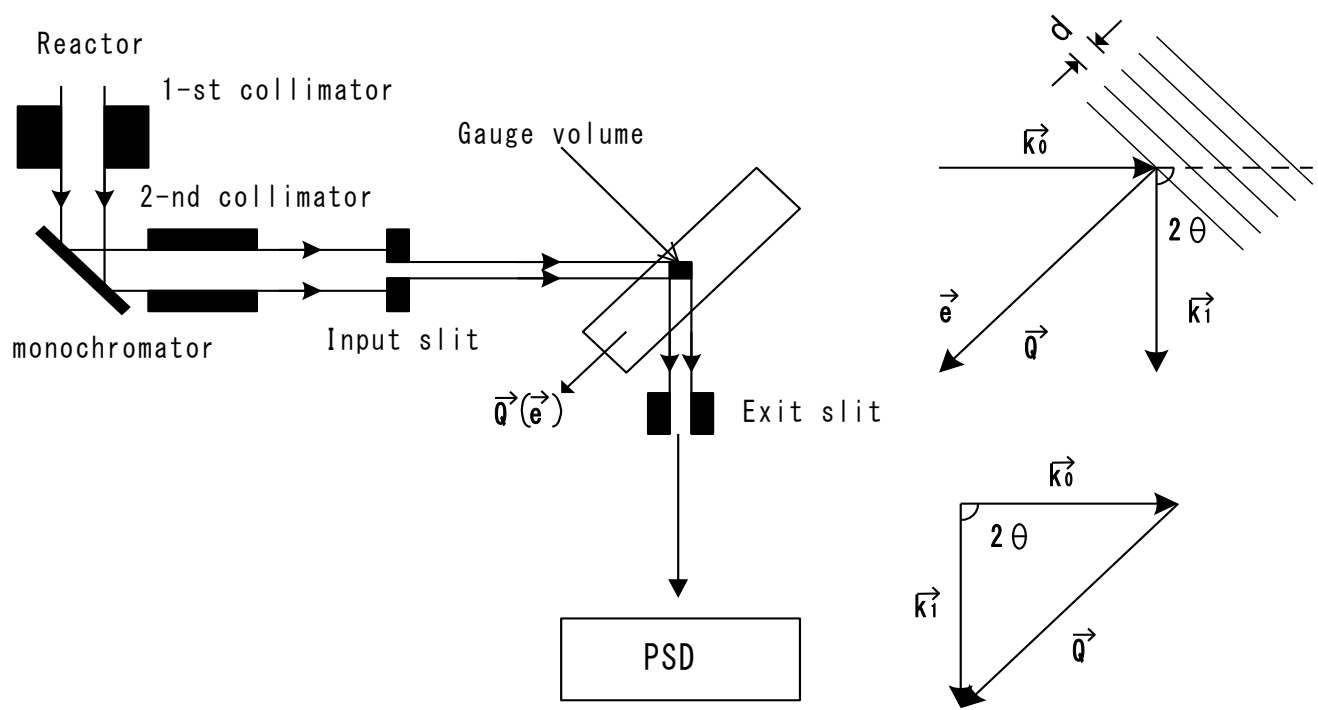

Figure 1. Schematic sketch of the neutron strain/stress scanner: $Q$-scattering vector perpendicular to the lattice planes, PSD - position sensitive detector, $d$ - lattice distance, $k_{0,1}$ - neutron wave vector, $\vartheta$ - Bragg angle.

\section{Results and Discussion}

The welded joint made of unalloyed C-Mn steel yield strength of $255 \mathrm{MPa}$ and tensile strength of 410 $\mathrm{MPa}$ has been used for identification of residual stress distribution. Two plates A and B thickness of $30 \mathrm{~mm}$ have been used to create vertical weld of spherical pressure vessel. Chemical composition of both plates is summarized in Table 1. Chemical composition of weld metal is shown in Table 2. Manual metal arc welding process using E-Boi spec. electrodes has been employed for the preparation of the weld. Macrostructure of the analysed welded joint is shown in Figure 3.

Table 1. Chemical composition of C-Mn steel used for spherical vessel.

\begin{tabular}{|l|c|c|c|c|c|c|c|c|c|c|}
\hline \multirow{2}{*}{ plate } & \multicolumn{10}{|c|}{ Mass concentration [\%] } \\
\cline { 2 - 11 } & $\mathbf{C}$ & $\mathbf{S i}$ & $\mathbf{M n}$ & $\mathbf{P}$ & $\mathbf{S}$ & $\mathbf{C u}$ & $\mathbf{N i}$ & $\mathbf{A l}$ & $\mathbf{C r}$ & $\mathbf{M o}$ \\
\hline A & 0,158 & 0,291 & 0,542 & 0,019 & 0,016 & 0,064 & 0,065 & 0,050 & 0,124 & 0,022 \\
\hline B & 0,185 & 0,246 & 0,405 & 0,017 & 0,012 & 0,056 & 0,073 & 0,036 & 0,148 & 0,056 \\
\hline 11418.1 & max. & max. & 0,50 & max. & max. & max. & max. & min. & max. & max. \\
according to & 0,20 & 0,35 & 1,40 & 0,030 & 0,025 & 0,30 & 0,30 & 0,020 & 0,25 & 0,08 \\
STN 41 1418 & & & & & & & & &
\end{tabular}

Table 2. Chemical composition of weld metal.

\begin{tabular}{|c|c|c|c|c|c|}
\hline \multicolumn{7}{|c|}{ Mass concentration [\%] } \\
\hline $\mathbf{C}$ & Mn & Si & P & S & Mo \\
\hline 0,090 & 0,587 & 0,257 & 0,023 & 0,012 & 0,410 \\
\hline
\end{tabular}




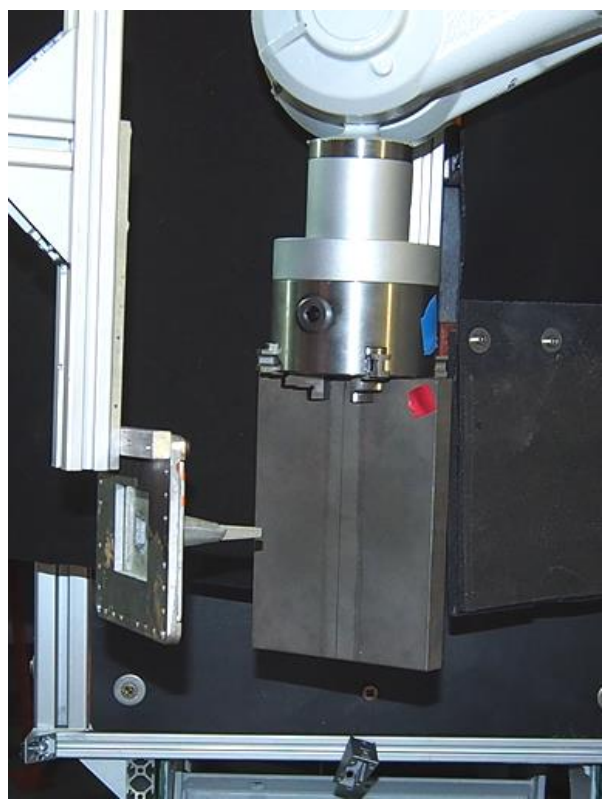

Figure 2. Photograph of the sample attached to a robotic arm, for neutron diffraction.

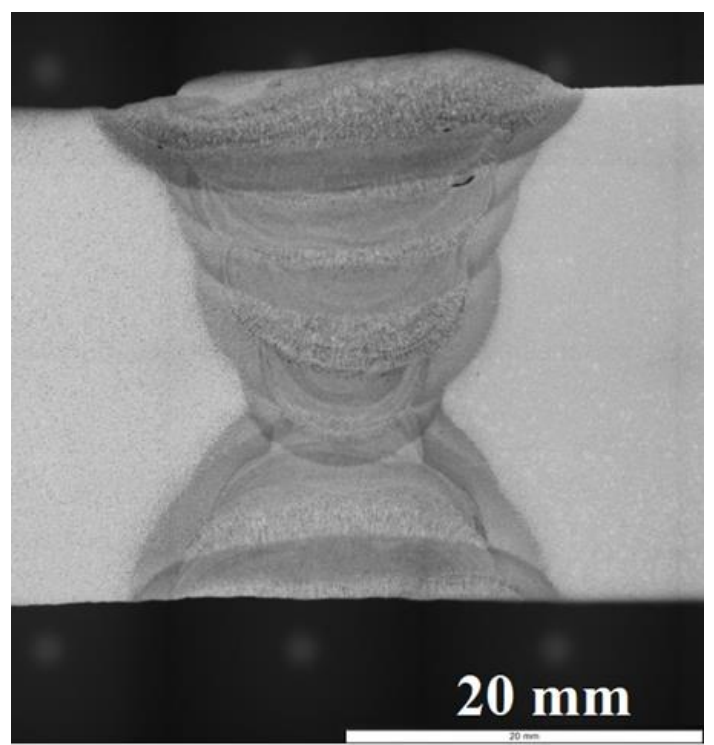

Figure 3. Macrostructure of the analysed welded joint.

Normal, transverse and longitudinal components have been measured for the through thickness positions $2 \mathrm{~mm}$ below the surface on the neutron diffraction. The relatively large defined sample gauge volume $(3 \mathrm{~mm} \times 3 \mathrm{~mm} \times 3 \mathrm{~mm}$ ) used for measurement close to the sample surface could induce pseudo-strains, due to the so-called surface effect. Several methods able to deal with this well-known phenomenon have been developed [6], often requiring extra measurements time. A recently described semi-empirical method requiring no extra calibration measurements could also be applied [7].

The measurements completed with the unalloyed $\mathrm{C}-\mathrm{Mn}$ steel material revealed that maximum residual stresses in the level of $300 \mathrm{MPa}$ are observed in the longitudinal direction, $150 \mathrm{MPa}$ in transversal and $200 \mathrm{MPa}$ in normal direction (perpendicular to the main face of the plate), as shown in Figure 4. 

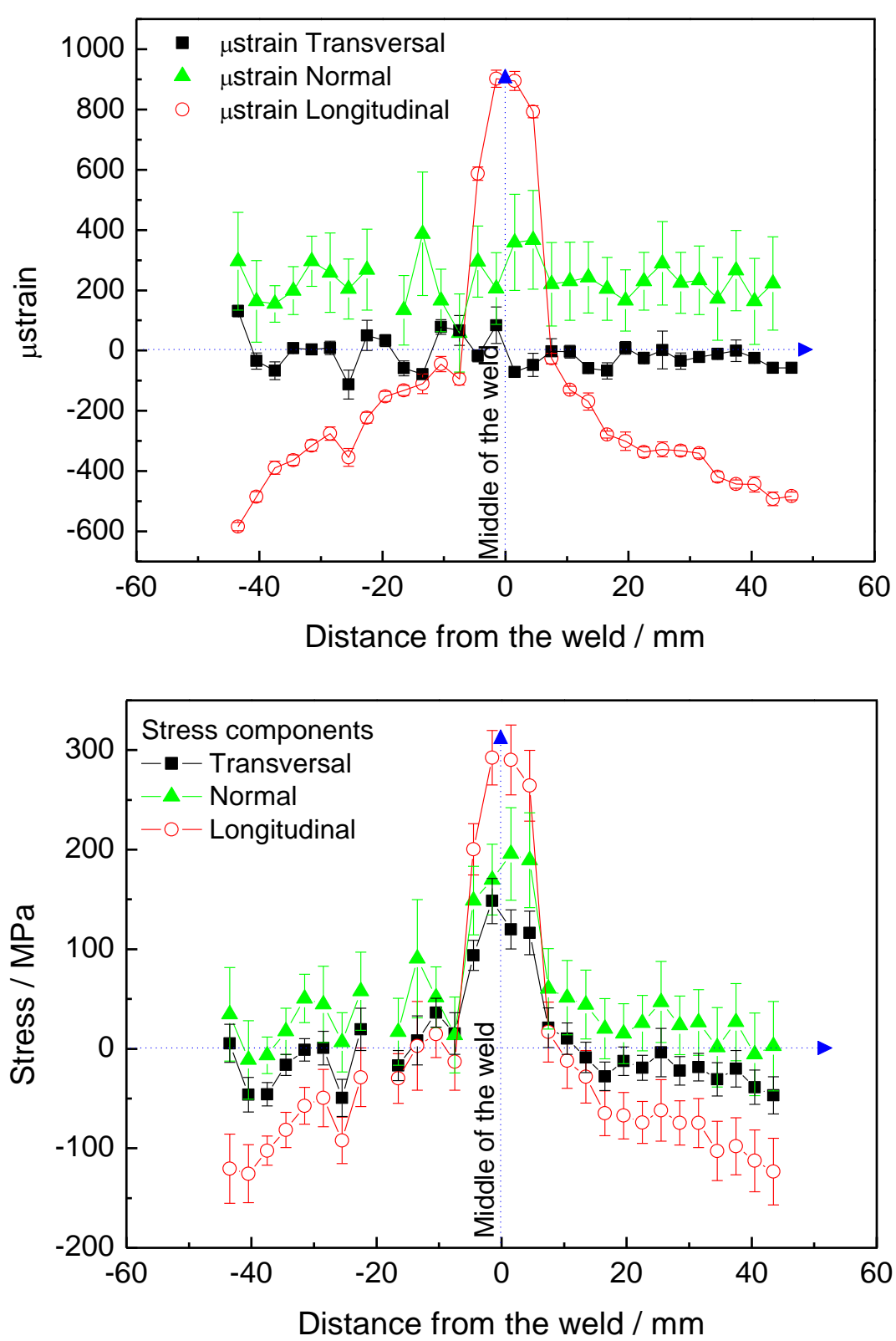

Figure 4. Microstrains and stresses versus the distance from the weld obtained by neutron diffraction.

\section{Conclusions}

Residual stress distribution in the vicinity of the weld taken out of spherical tank used for storage of anhydrous ammonia has been determined using neutron diffraction. The measured tensile stresses, 2 mm below the sample surface, with a value of $\sim 300 \mathrm{MPa}$, are higher than the residual stresses measured deeper in the sample. Consequently, the results were used for calculation of the critical crack size in order to take decision concerning the necessary repair of the pressure vessel.

\section{Acknowledgements}


This work was supported by the Czech Science Foundation project No.16-08803J. Measurements were carried out with the support of the Ministry of Education, Youth and Sports (CANAM infrastructure of the NPI CAS Rež - project No. LM2015056, and infrastructure "Reactors LVR-15 and LR-0" - project No. LM2015074).

\section{References}

1. L. Mráz, C. Hervoches, M. Vrána, P. Mikula, P. Baksa, and J. Bošanský, EAN 2017 - 55th Conference on Experimental Stress Analysis, 133-138 (2017).

2. P. Mikula, M. Vrana, P. Lukas, J. Saroun, P. Strunz, H.J. Ullrich and V. Wagner, Proc. of ICRS-5, T. Ericsson, M. Odén and A. Andersson (Eds.) 2, 721-725 (1997).

3. Ch.H. Hervoches, P. Mikula, M. Vrána, EAN 2015 - 53rd Conference on Experimental Stress Analysis, 119-120 (2015).

4. P. Mikula, Materials Structure 13, 51-62 (2006).

5. C. Randau, U. Garbe, and H. G. Brokmeier, J. Appl. Cryst. 44, 641-646 (2011).

6. M.T. Hutchings, P.J. Withers, T.M. Holden, T. Lorentzen, Introduction to the Characterization of Residual Stresses by Neutron Diffraction, CRC Press, Taylor and Francis, London (2005).

7. J. Šaroun, J. Rebelo-Kornmeier, J. Gibmeier, M. Hofmann, Physica B: Condensed Matter, in press, https://doi.org/10.1016/j.physb.2018.01.013 (2018). 